\title{
Exposure to lower red to far-red light ratios improve tomato tolerance to salt stress
}

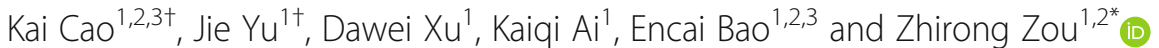

\begin{abstract}
Background: Red (R) and far-red (FR) light distinctly influence phytochrome-mediated initial tomato growth and development, and more recent evidence indicates that these spectra also modulate responses to a multitude of abiotic and biotic stresses. This research investigated whether different R: FR values affect tomato growth response and salinity tolerance. Tomato seedlings were exposed to different R: FR conditions (7.4, 1.2 and 0.8) under salinity stress (100 mM NaCl), and evaluated for their growth, biochemical changes, active reactive oxygen species (ROS) and ROS scavenging enzymes, pigments, rate of photosynthesis, and chlorophyll fluorescence.

Results: The results showed that under conditions of salinity, tomato seedlings subjected to a lower R: FR value (0.8) significantly increased both their growth, proline content, chlorophyll content and net photosynthesis rate $(\mathrm{Pn})$ , while they decreased malondialdehyde (MDA) compared to the higher R: FR value (7.4). Under conditions of salinity, the lower $\mathrm{R}: \mathrm{FR}$ value caused a decrease in both the superoxide anion $\left(\mathrm{O}_{2}^{-{ }^{-}}\right)$and in hydrogen peroxide $\left(\mathrm{H}_{2} \mathrm{O}_{2}\right)$ generation, an increase in the activities of superoxidase dismutase (SOD, EC 1.15.1.1), peroxidase (POD, EC 1. 11.1.7) and catalase (CAT, EC 1.11.1.7). Tomato seedlings grown under the lower R: FR value and conditions of salinity showed a higher actual quantum yield of photosynthesis (DPSII), electron transport rate (ETR), and photochemical quenching (qP) than those exposed to a higher R: FR, indicating overall healthier growth. However, the salinity tolerance induced at the lower R: FR condition disappeared in the tomato phyB1 mutant.

Conlusion: These results suggest that growing tomato with a lower R: FR value could improve seedlings' salinity tolerance, and phytochrome B1 play an very important role in this process. Therefore, different qualities of light can be used to efficiently develop abiotic stress tolerance in tomato cultivation.
\end{abstract}

Keywords: Tomato, R: FR ratio, Phytochrome B1, Antioxidant system, chlorophyll fluorescence

\section{Background}

Plant growth and development are controlled by various signaling pathways that enable them to modulate a wide range of molecular and biochemical responses to changes in their environment. Light is one of the most important environmental factors for plant development. To adapt to different light conditions, plants evolved several families of photoreceptors covering both the visible and the UV-A/B region of the spectrum [1-5].

Phytochromes, which absorb red (R) and far-red (FR) light, are the most characterized photoreceptors in

\footnotetext{
*Correspondence: zouzhirong2005@hotmail.com

${ }^{\dagger}$ Kai Cao and Jie Yu contributed equally to this work.

${ }^{1}$ Horticulture College, Northwest A\&F University, Yangling, Shaanxi, China

${ }^{2}$ The Agriculture Ministry Key Laboratory of Agricultural Engineering in the

Middle and Lower Reaches of Yangze River, Nanjing, China

Full list of author information is available at the end of the article
}

plants and are important in mediating many aspects of physiological development. Phytochromes, composed of photochromic proteins, are $\sim 130 \mathrm{kDa}$ peptides with a covalently linked linear tetrapyrrole bilin chromophore, that exist as two photo-interconvertible isomeric forms: the red-light-absorbing form (Pr), which is biologically inactive, and the far-red-light-absorbing form (Pfr), which is biologically active [6]. Upon excitation by $R$ or FR light (producing a high or low R: FR ratio, respectively), the phytochrome converts the Pr into the Pfr form, or vice versa $[2,6]$.The conversion between $\operatorname{Pr}$ and PFr synchronizes plant development with the light environment, which causes changes in the expression of genes involved in photomorphogenesis [7-9].

Besides regulating photomorphogenesis, phytochromes also play an essential role in adapting to different sources of abiotic plant stress [2,10-15]. The tomato

(c) The Author(s). 2018 Open Access This article is distributed under the terms of the Creative Commons Attribution 4.0 International License (http://creativecommons.org/licenses/by/4.0/), which permits unrestricted use, distribution, and 
phytochromes B1 and B2 mainly act as negative regulators of growth, pigment maintenance and osmoprotectant accumulation during responses to the different abiotic stresses. However, phyA mutant showed similar growth variations under different abiotic stresses when compared to the wild genotype [10]. Indorf et al. [12] found that phyA, phyB and phyAphyB Arabidopsis thaliana mutants showed a reduced expression of salt tolerance genes, and the expression of these genes were also altered by exposure to different light conditions, suggesting that the phytochrome family contributes to salinity stress responses. Compared with the wild type, rice $p h y B$ deficiency causes both reduced total leaf area and reduced transpiration per unit leaf area, which reduced water loss and improved drought tolerance of phyB mutants [16]. In fact, $p h y B$ seems to be a fundamental component of many plants responses to abiotic stressors.

Soil salinity is a major threat to global food security. During salinity stress, plants have evolved a complex survival response that involves the coordinated action of many physiological and genetic processes, including control of water loss through stomata, ion sequestration, metabolic adjustment, osmotic adjustment, and antioxidative defense [17-20]. The raised level of reactive oxygen species (ROS) under salinity stress such as superoxide $\left(\mathrm{O}_{2}{ }^{--}\right)$and $\mathrm{OH}^{*}$ radicals, peroxynitrite, and $\mathrm{H}_{2} \mathrm{O}_{2}$, and the failure of ROS-scavenging mechanisms leads to oxidative stress, damage to macromolecules, and eventually cell death $[18,21]$. The increasing activity of antioxidant enzymes (SOD, CAT, POD, etc.) correlate with the level of salt tolerance [22, 23]. Moreover, salt tolerance can be improved when some antioxidant enzymes are overexpressed [24, 25]. Salinity tolerant hyperactive phytochrome mutant overexpression lines are associated with decreased $\mathrm{H}_{2} \mathrm{O}_{2}$ levels and significantly increased enzymatic activities of the major ROS scavengers, when compared with the wild type [26].

Chlorophyll's concentration and composition directly influence photosynthetic rate. The effects of environmental stresses on chlorophyll metabolism such as salt stress, light wavelength, and metals, have been studied in plants $[27,28]$. There is an observed salinity-induced decrease in chlorophyll, which may be due to a decrease in 5-aminolaevulinic acid accumulation [27]. Knowing the R: FR ratio can provide information about the shade, daylight, and seasonal environment that a plant was grown under, via information about the associated regulation of leaf chlorophyll synthesis, photosynthesis rate, and PSII electron transport [2, 26, 29].

Previous studies have indicated that a well-organized interaction exists between phytochrome and abiotic stresses in plants. However, the exact relationship between the R: FR value and salinity stress on chlorophyll synthesis, photosynthesis rate, and PSII electron transport in the tomato is still elusive. In the present study, the effect of different R: FR values and salinity on tomato seedling growth, biochemicals, ROS and ROS scavenging enzymes, pigment, photosynthesis, and chlorophyll fluorescence is clarified. By clarifying the interaction between R:FR and salinity, we may be able to produce varieties of tomato and other vital food crops that are able to better tolerate and survive increasingly saline soils in diverse environments.

\section{Results}

\section{Lower R: FR promoted tomato seedling growth under salinity stress}

Data showing the effect of a range of R: FR conditions on the growth parameters of tomato seedlings under salinity stress are in Table 1 . In general, salinity caused a significant reduction in plant height, stem diameter, fresh and dry weight of root, stem and leaf, as compared to control plants in the same light conditions. Under normal conditions with no salinity in T3, there was a substantial increase in plant height (42.70\%), fresh and dry weight (38.51 and $25.59 \%$, respectively), as compared to $\mathrm{T} 1$, whereas in $\mathrm{T} 2$, there was a larger increase of 23.87, 47.17 and $39.29 \%$ respectively, when compared with T1 (Table 1). Under the salinity condition, in T6, the lower R: FR led to a substantial increase in plant height (49.53\%), fresh and dry weight (93.17 and $104.88 \%$, respectively), whereas in T5 there was a lower increase of $22.14,44.95$ and $50.00 \%$, respectively, when compared with T3 (Table 1).

Under normal conditions, the growth of tomato seedlings was better with an R: FR of 1.2, compared to a higher ratio of 7.4. However, under the salinity condition, the lower R: FR of 0.8 provided tomato seedlings with greater salinity tolerance.

\section{A lower R: FR exhibited higher soluble protein and proline, while MDA amount and electrolytic leakage decreased under the salinity condition}

To quantify the effect of salinity stress treatments on the biochemistry of tomato seedlings under different R: FR conditions, the soluble protein, proline, MDA and electrolytic leakage were analyzed. An increased accumulation of proline and soluble protein in plant tissues subjected to stress indicates an effective plant stress response at the metabolic level [26]. It was found that proline and soluble protein accumulated in the greatest quantities under the salinity condition and the lower R: FR of 0.8. After 8 days with the salinity treatment, the amount of proline and soluble protein in the leaf tissues increased by 63.58 and $12.50 \%$ under the lower R: FR treatment as compared to the highest ratio tested (Fig. 1a, b). The amount of MDA and the percentage of electrolytic leakage are usually used as tools to assess the 
Table 1 Effects of different R: FR values on plant height, stem diameter, fresh and dry weights of root, stem, and leaf in tomato seedlings under salinity stress in wild type (WT) and phytochrome B1 mutant (phyB1 mutant)

\begin{tabular}{|c|c|c|c|c|c|c|c|c|}
\hline \multicolumn{3}{|l|}{ Treatments } & \multirow{2}{*}{$\frac{T 1}{18.43 \pm 0.65 c}$} & \multirow{2}{*}{$\frac{\mathrm{T} 2}{22.83 \pm 0.82 \mathrm{~b}}$} & \multirow{2}{*}{$\frac{T 3}{26.30 \pm 0.75 a}$} & \multirow{2}{*}{$\frac{\mathrm{T} 4}{12.92 \pm 0.55 \mathrm{e}}$} & \multirow{2}{*}{$\frac{T 5}{15.78 \pm 0.78 d}$} & \multirow{2}{*}{$\begin{array}{l}\text { T6 } \\
19.32 \pm 0.65 c\end{array}$} \\
\hline \multirow[t]{10}{*}{ WT } & \multicolumn{2}{|c|}{ Plant height $(\mathrm{cm})$} & & & & & & \\
\hline & \multicolumn{2}{|c|}{ Stem Diameter $(\mathrm{mm})$} & $7.37 \pm 0.55 a$ & $6.29 \pm 0.46 b$ & $5.89 \pm 0.50 b c$ & $5.66 \pm 0.55 c$ & $5.43 \pm 0.53 c$ & $4.61 \pm 0.17 d$ \\
\hline & \multirow[t]{4}{*}{ Fresh mass (g) } & Root & $5.66 \pm 0.22 b$ & $6.91 \pm 0.41 a$ & $5.77 \pm 0.40 \mathrm{~b}$ & $3.00 \pm 0.20 d$ & $4.33 \pm 0.35 c$ & $5.58 \pm 0.30 \mathrm{~b}$ \\
\hline & & Stem & $6.38 \pm 0.25 c$ & $9.57 \pm 0.34 a$ & $10.94 \pm 0.34 a$ & $2.73 \pm 0.16 \mathrm{e}$ & $4.47 \pm 0.28 d$ & $5.89 \pm 0.29 c$ \\
\hline & & Leaf & $14.44 \pm 0.51 c$ & $22.49 \pm 0.55 a$ & $19.96 \pm 0.47 b$ & $7.43 \pm 0.37 e$ & $10.29 \pm 0.47 d$ & $13.96 \pm 0.55 c$ \\
\hline & & In total & $26.48+0.97 c$ & $38.97+0.86 a$ & $36.68+1.08 b$ & $13.17+0.90 e$ & $19.09+1.06 d$ & $25.44+1.12 c$ \\
\hline & \multirow[t]{4}{*}{ Dry mass (g) } & Root & $0.28 \pm 0.02 b c$ & $0.37 \pm 0.02 \mathrm{a}$ & $0.30 \pm 0.03 b$ & $0.14 \pm 0.02 \mathrm{e}$ & $0.20 \pm 0.02 d$ & $0.26 \pm 0.01 c$ \\
\hline & & Stem & $0.23 \pm 0.02 c$ & $0.35 \pm 0.02 b$ & $0.41 \pm 0.02 a$ & $0.16 \pm 0.03 d$ & $0.24 \pm 0.02 c$ & $0.25 \pm 0.02 c$ \\
\hline & & Leaf & $1.16 \pm 0.05 c$ & $1.61 \pm 0.04 a$ & $1.40 \pm 0.03 b$ & $0.51 \pm 0.04 e$ & $0.78 \pm 0.04 d$ & $1.13 \pm 0.04 c$ \\
\hline & & In total & $1.68+0.07 c$ & $2.34+0.06 a$ & $2.11+0.04 b$ & $0.82+0.08 e$ & $1.23+0.08 d$ & $1.68+0.02 c$ \\
\hline \multirow[t]{10}{*}{ phyB1 mutant } & \multicolumn{2}{|c|}{ Plant height $(\mathrm{cm})$} & $25.18 \pm 0.79 a$ & $24.90 \pm 0.74 a$ & $25.21 \pm 0.51 a$ & $16.64 \pm 0.51 b$ & $16.10 \pm 0.55 b$ & $16.61 \pm 0.67 b$ \\
\hline & \multicolumn{2}{|c|}{ Stem Diameter (mm) } & $5.61 \pm 0.23 a$ & $5.66 \pm 0.23 a$ & $5.50 \pm 0.13 a$ & $4.44 \pm 0.25 b$ & $4.49 \pm 0.30 \mathrm{~b}$ & $4.30 \pm 0.20 \mathrm{~b}$ \\
\hline & \multirow[t]{4}{*}{ Fresh mass (g) } & Root & $2.52 \pm 0.10 a$ & $2.66 \pm 0.13 a$ & $2.49 \pm 0.15 a$ & $1.68 \pm 0.04 b$ & $1.65 \pm 0.14 b$ & $1.70 \pm 0.06 b$ \\
\hline & & Stem & $6.37 \pm 0.35 a$ & $6.39 \pm 0.24 a$ & $6.33 \pm 0.25 a$ & $3.59 \pm 0.17 b$ & $3.51 \pm 0.21 b$ & $3.42 \pm 0.14 b$ \\
\hline & & Leaf & $14.47 \pm 0.55 a$ & $14.41 \pm 0.45 a$ & $14.12 \pm 0.53 a$ & $7.94 \pm 0.78 b$ & $8.17 \pm 0.17 b$ & $7.96 \pm 0.07 b$ \\
\hline & & In total & $23.36 \pm 0.47 a$ & $23.47 \pm 0.16 a$ & $22.95 \pm 0.24 a$ & $13.21 \pm 0.58 b$ & $13.33 \pm 0.10 b$ & $13.09 \pm 0.16 b$ \\
\hline & \multirow[t]{4}{*}{ Dry mass (g) } & Root & $0.138 \pm 0.005 a$ & $0.142 \pm 0.006 a$ & $0.141 \pm 0.015 a$ & $0.087 \pm 0.006 b$ & $0.089 \pm 0.010 b$ & $0.093 \pm 0.015 b$ \\
\hline & & Stem & $0.254 \pm 0.017 a$ & $0.262 \pm 0.026 a$ & $0.265 \pm 0.015 a$ & $0.126 \pm 0.017 b$ & $0.123 \pm 0.005 b$ & $0.128 \pm 0.010 b$ \\
\hline & & Leaf & $1.133 \pm 0.083 a$ & $1.126 \pm 0.101 a$ & $1.066 \pm 0.100 a$ & $0.716 \pm 0.011 b$ & $0.773 \pm 0.015 b$ & $0.763 \pm 0.057 b$ \\
\hline & & In total & $1.516 \pm 0.083 a$ & $1.533 \pm 0.100 a$ & $1.473 \pm 0.120 a$ & $0.920 \pm 0.017 b$ & $0.980 \pm 0.010 b$ & $0.971 \pm 0.072 b$ \\
\hline
\end{tabular}

The values (mean $\pm \mathrm{SE}, n=6$ ) with different letter within columns are statistically different $(P \leq 0.05)$ according to Duncan's multiple range test. T1, 0 mM NaCl + 7.4 R: FR; T2, 0 mM NaCl + 1.2 R: FR; T3, 0 mM NaCl + 0.8 R: FR; T4, 100 mM NaCl + 7.4 R: FR; T5, 100 mM NaCl + 1.2 R: FR; T6, 100 mM NaCl + 0.8 R: FR

severity of oxidative damage, the degree of plant sensitivity, and cell membrane injury [28, 30]. Figure 1 showed that the lower R: FR condition largely decreased MDA and electrolytic leakage percentage under salinity stress. After 8 days of salinity treatment under the lower R: FR, the amount of MDA and electrolytic leakage percentage in the leaf tissue decreased by 30.53 and $15.60 \%$, compared with the highest R: FR condition (Fig. 1c, d). Under the salinity condition, the lower R: FR ratio led to decrease in both MDA amount and electrolytic leakage, but increase in proline amount and accumulation of soluble protein, which made tomato seedlings more tolerant to salinity stress.

\section{The lower R: FR treatment accumulated less ROS and showed a higher activity of ROS scavenging enzymes under the salinity condition}

To observe the effect of salinity stress treatments on plant antioxidant system under the lower R: FR condition, $\mathrm{H}_{2} \mathrm{O}_{2}$ and $\mathrm{O}_{2}{ }^{\cdot-}$ levels and enzymatic activities of the major ROS scavengers were measured. $\mathrm{H}_{2} \mathrm{O}_{2}$ and $\mathrm{O}_{2}{ }^{--}$are common ROS produced in plants, and are indicators of optimal health, as they are typically produced following exposure to salinity stress [31, 32]. In this experiment, the accumulation of $\mathrm{H}_{2} \mathrm{O}_{2}$ and $\mathrm{O}_{2}{ }^{\cdot-}$ were significantly enhanced after salinity treatment, and after 8 days, the seedlings grown under the higher R: FR treatment showed almost 1.3-1.5-fold higher levels of $\mathrm{H}_{2} \mathrm{O}_{2}$ and $\mathrm{O}_{2}{ }^{-}$than the corresponding tomato seedlings grown under the lower R: FR treatment (Fig. 2a, b). The activity of SOD, POD and CAT enzymes were notably increased in response to salinity alone, but in combination with the lower R: FR treatment, enzyme activity was comparatively much higher (Fig. 2c, d, e). The activity of major ROS-scavenging enzymes revealed that tomato seedlings grown under the lower R: FR treatment exhibited an improved ROS scavenging system under salinity stress compared to that of tomato seedlings grown under the higher R: FR treatment.

\section{The lower R: FR treatment accumulated more photosynthetic pigments and exhibited increased photosynthetic efficiency}

Measurements of chlorophyll, carotenoid, photosynthesis rate, and fluorescence were taken using leaf number two below the youngest fully expanded leaf. Under normal conditions, chlorophyll a had a tendency to decrease with the decrease of R: FR values, no significant differences in chlorophyll $\mathrm{b}$ and net photosynthesis rate were observed under different R: FR values, and carotenoid showed a 

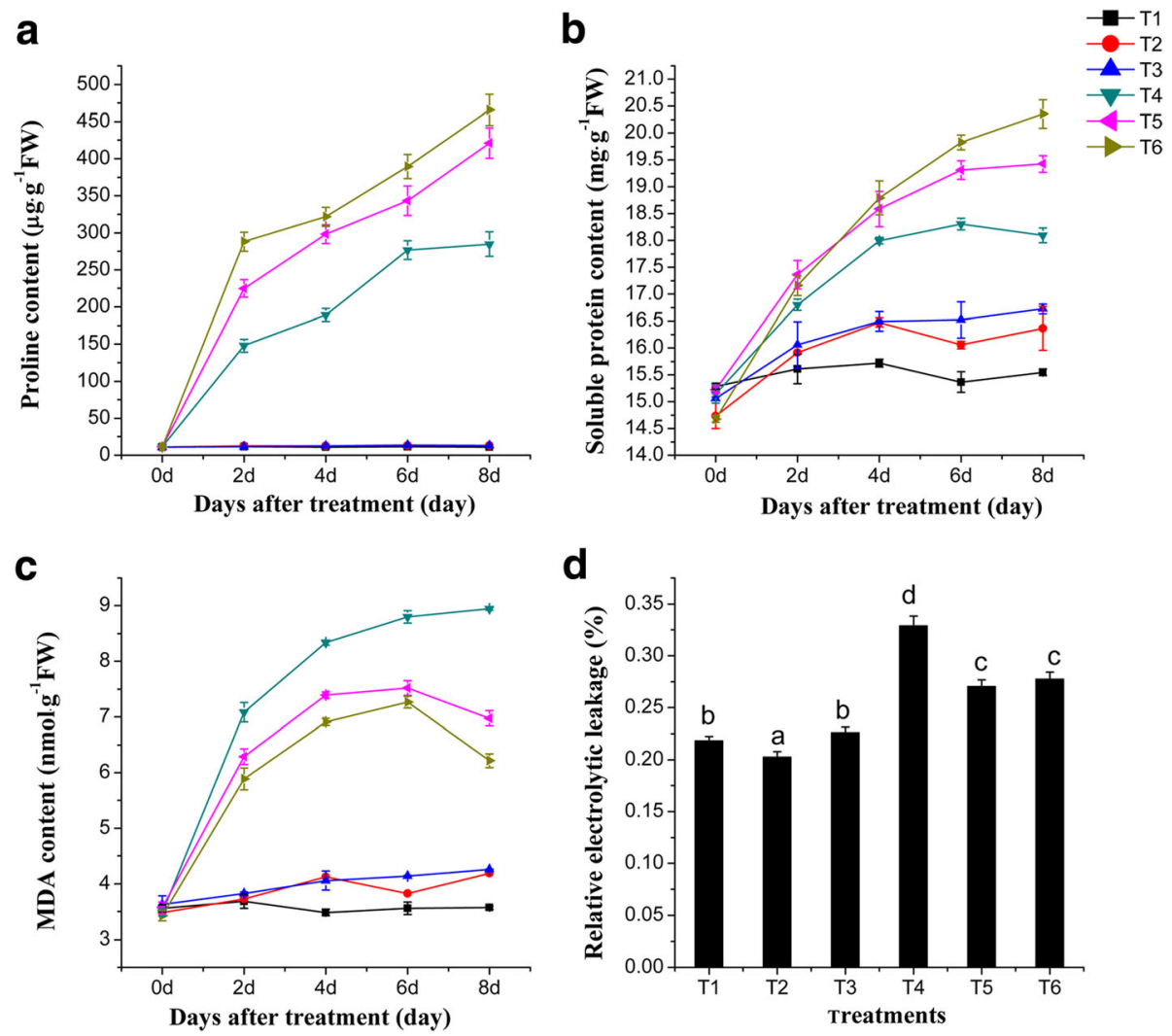

Fig. 1 Effects of different R: FR values on proline, soluble protein, and MDA content, and relative electrolyte leakage in tomato seedlings under salinity stress. a proline content. b soluble protein content. c MDA content. Proline, soluble protein and MDA contents were measured 0, 2, 4, 6, and 8 days after exposure to the salinity treatment. $\mathbf{d}$ relative electrolyte leakage, measured 8 days after salinity treatment. T1, $0 \mathrm{mM} \mathrm{NaCl}+7.4 \mathrm{R}$ : FR; T2, $0 \mathrm{mM} \mathrm{NaCl}+1.2 \mathrm{R}: \mathrm{FR} ; \mathrm{T} 3,0 \mathrm{mM} \mathrm{NaCl}+0.8 \mathrm{R}: \mathrm{FR} ; \mathrm{T} 4,100 \mathrm{mM} \mathrm{NaCl}+7.4 \mathrm{R}: \mathrm{FR} ; \mathrm{T} 5,100 \mathrm{mM} \mathrm{NaCl}+1.2 \mathrm{R}: \mathrm{FR} ; \mathrm{T} 6,100 \mathrm{mM} \mathrm{NaCl}+0.8 \mathrm{R}: \mathrm{FR}$. Vertical bars on the lines represent the SE $(n=5)$, Bars with different letters are significantly different at the 0.05 level (Duncan's multiple range test)

significant difference, not correlated to the R: FR values (Fig. 3a, b, c). However, after the salinity treatment, chlorophyll a, chlorophyll b, and the net photosynthesis rate increased significantly when R: FR value is 0.8 , compared with R: FR value is 7.4 (Fig. 3a, b, c). The actual quantum yield of photosynthesis (ФPSII), electron transport rate (ETR), and photochemical quenching $(\mathrm{qP})$ are inversely proportional to the damage in the PSII reaction centers [31, 32]. These widely used chlorophyll fluorescence parameters indicate how well a plant grows under conditions when higher than normal salinity is present. In the present study, a similar trend was also observed with ФPSII, ETR, and qP, in which these parameters increased substantially under the lower R: FR treatment (Fig. 3d, e, f), suggesting that a lower R: FR could activate PSII reaction centers and consequently alleviate negative impacts of salinity stress on tomato seedlings.

\section{Phytochrome B1 is involved in the regulation of lower $\mathrm{R}$ : FR on tomato seedlings salinity tolerance}

When phytochrome B1 activity was quantified to test for its influence on tomato salinity tolerance, results showed that in the tomato phyB1 mutant, the salinity treatment decreased plant height, stem diameter, fresh and dry weight of root, stem and leaf, chlorophyll and carotenoid amount, photosynthesis rate, ФPSII and MDA, and increased proline and $\mathrm{H}_{2} \mathrm{O}_{2}$ content, but these parameters did not significantly change when different R: FR treatments were applied under salinity conditions (Table 1, Fig.4). In wild type tomato, different R: FR treatments had a significant influence on these parameters under salinity conditions, however, the influence disappeared in the phyB1 mutant. These results showed that phytochrome B1 mediated tomato seedlings tolerate high salinity conditions under different R: FR treatments.

\section{Discussion}

Red (R) and far-red (FR) light are abiotic factors that are particularly important for plant growth and development. The ratio of red to far-red light (R: FR) is often used to signal the proximity of neighboring or canopy vegetation, as chlorophyll selectively absorbs 655$665 \mathrm{~nm}$ light while transmitting 725-735 nm light. The 


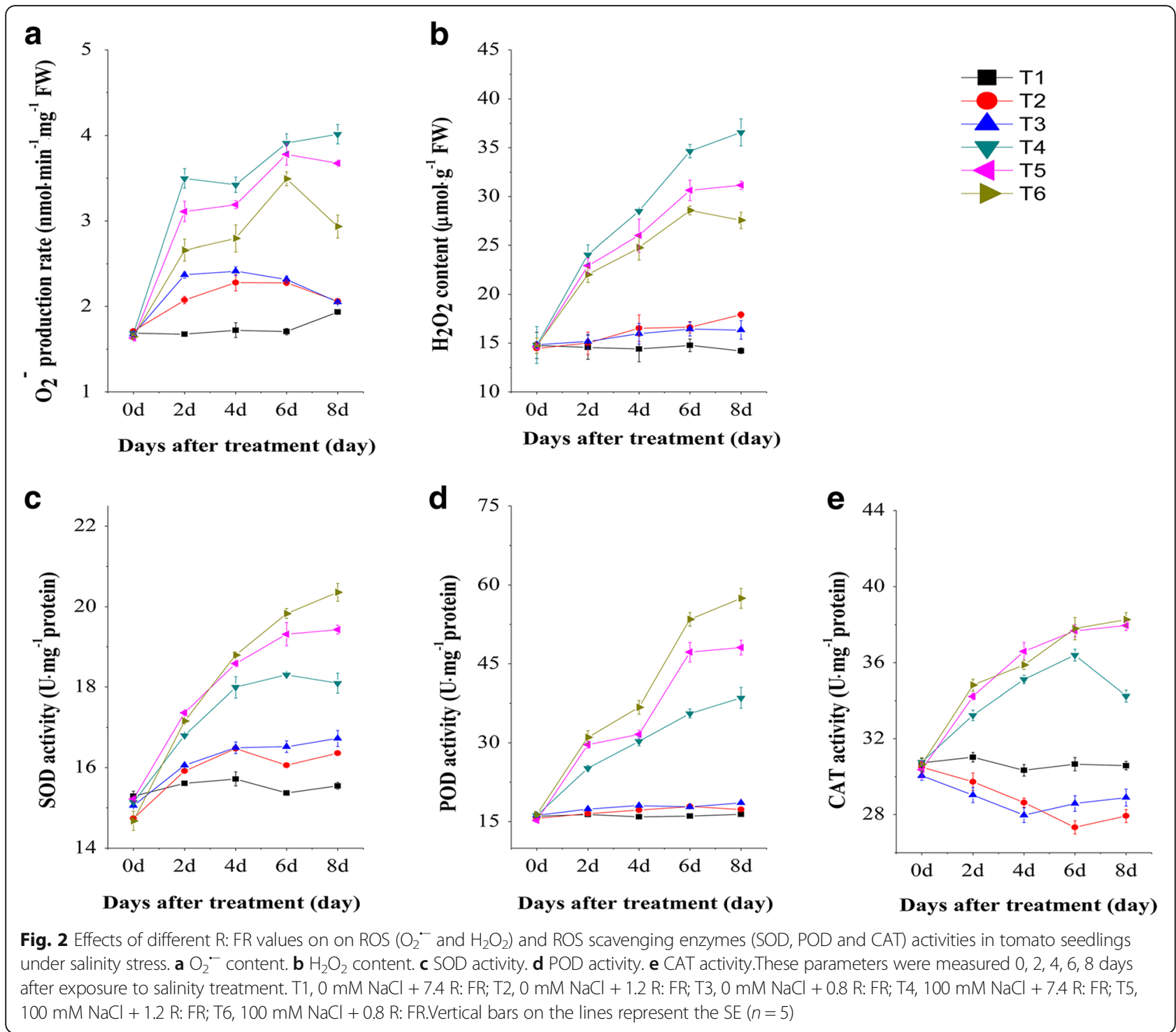

ratio can also be used to sense changes in daylength or seasonal variation, as the R: FR is low (about 0.6-0.8) at the beginning and end of the photoperiod, and at its maximum at solar noon (about 1.0 to 1.3 ) $[33,34]$. The $\mathrm{R}$ : FR value can trigger many plant morphological responses, including promotion of shoot elongation and reduction of stem diameter in dicotyledonous and ornamental species from a low R: FR, either during the daytime or only at the end of the day [29, 35]. During salinity-induced stress, plants experience reduced growth and development, but can respond in various ways to withstand the stress. In this study, without salinity treatment, plant height was increased, but stem diameter were comparatively reduced under a lower R: FR treatment (Table 1). Similarly, Yan et al. [36] reported that soybean seedling height was significantly increased while the stem diameter was decreased in lower R: FR treatment conditions. However, under a salinity treatment, applying a lower R: FR promoted tomato seedlings growth, increased plant height, fresh and dry weight of root, stem and leaf. Results from this research suggest that a lower R: FR condition could help alleviate the impact of salinity on the development of tomato seedlings, and that more generally, the value of R: FR influences salinity stress tolerance as a consequence of morphological responses. To better quantify and operationalize this finding, further studies on the relationship of salinity tolerance with light quality are necessary.

A given plant's ability to tolerate salinity is dependent on multiple biochemical pathways that lead to the production of osmotically dynamic metabolites, free radicals, and specific proteins that manage ion and water flux $[28,37]$. Likewise, the R: FR ratio also regulates a large range of biochemical processes throughout a 


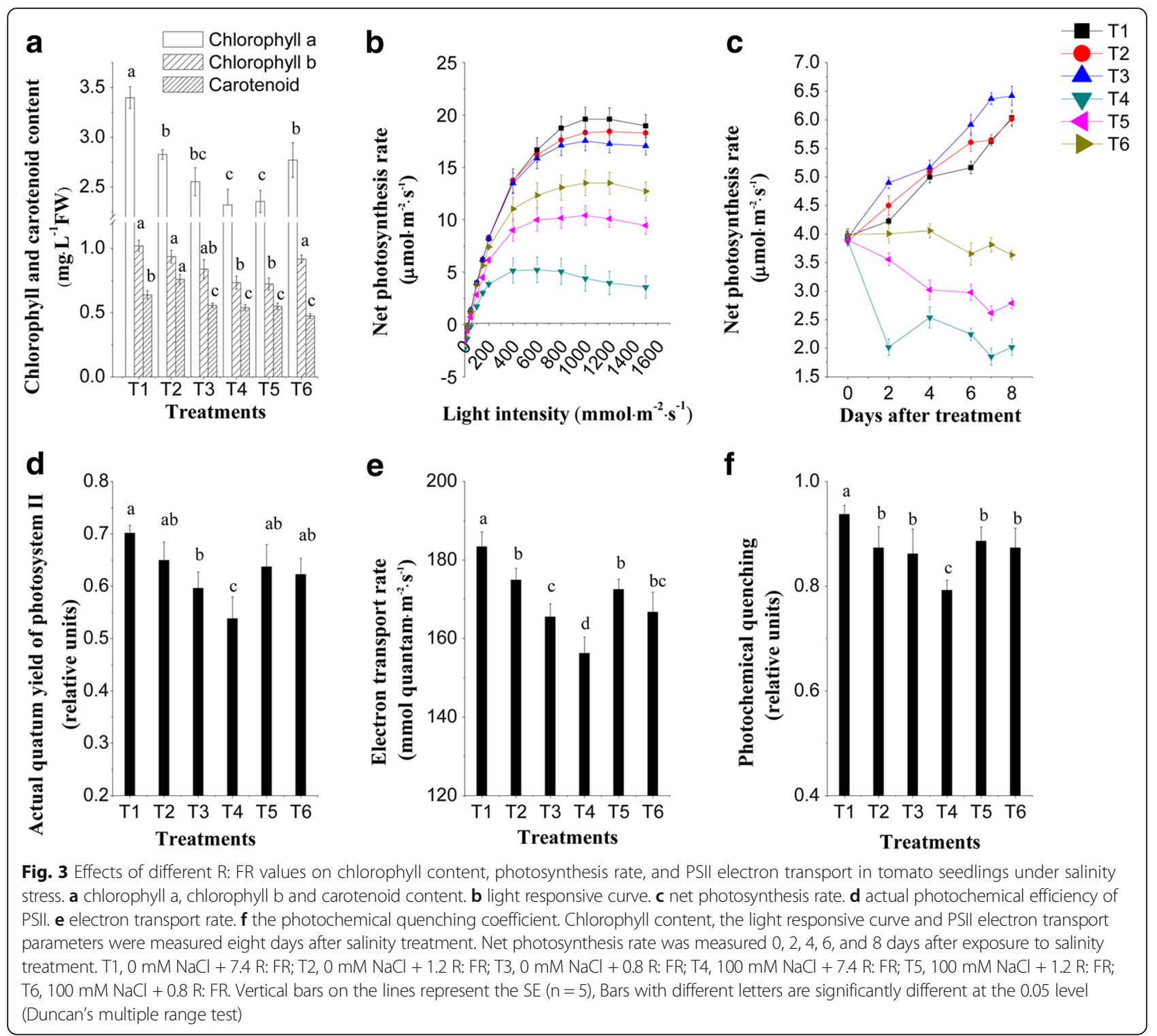

plant's life [29]. Proline plays a crucial role in stabilizing the subcellular structures and scavenging free radicals [26]. MDA is the decomposition product of polyunsaturated fatty acids of biomembranes and is used to assess the severity of oxidative damage [28]. Electrolyte leakage is an important index of the plant cell's permeability, which plays an important role in the study of plant salt stress [30]. Our results indicated that a lower R: FR of 0.8 under salinity conditions led to a decrease in MDA and electrolytic leakage, and an increase in proline and soluble protein content (Fig. 1). These results suggest that salt-stressed tomato seedlings grown under lower R: FR conditions encountered less cellular damage and lipid peroxidation.

$\mathrm{H}_{2} \mathrm{O}_{2}$ and $\mathrm{O}_{2}{ }^{-{ }^{-}}$are reactive oxygen species (ROS), and cause oxidative stress at high concentrations [21]. In this study, accumulation of $\mathrm{H}_{2} \mathrm{O}_{2}$ and $\mathrm{O}_{2}{ }^{--}$from salinity stress was decreased when seedlings were exposed to a lower R: FR condition. Plant cells have developed different mechanisms to alleviate the excess ROS, and keep the balance of the formation and removal of ROS [38]. An increase in antioxidant enzymes (SOD, POD and CAT) protects the plants from oxidative damage, and were shown to be highest in the lower R: FR condition under salinity, suggesting that the lower R: FR condition induced an efficient ROS scavenging mechanism. Similar findings of low accumulation of ROS and higher antioxidant enzyme activity in stress-tolerant plants have been reported previously $[26,28]$. Although the mechanism of light quality regulated ROS generation and scavenging remains unclear, there are reports indicating that light quality induces the synthesis of various protective 


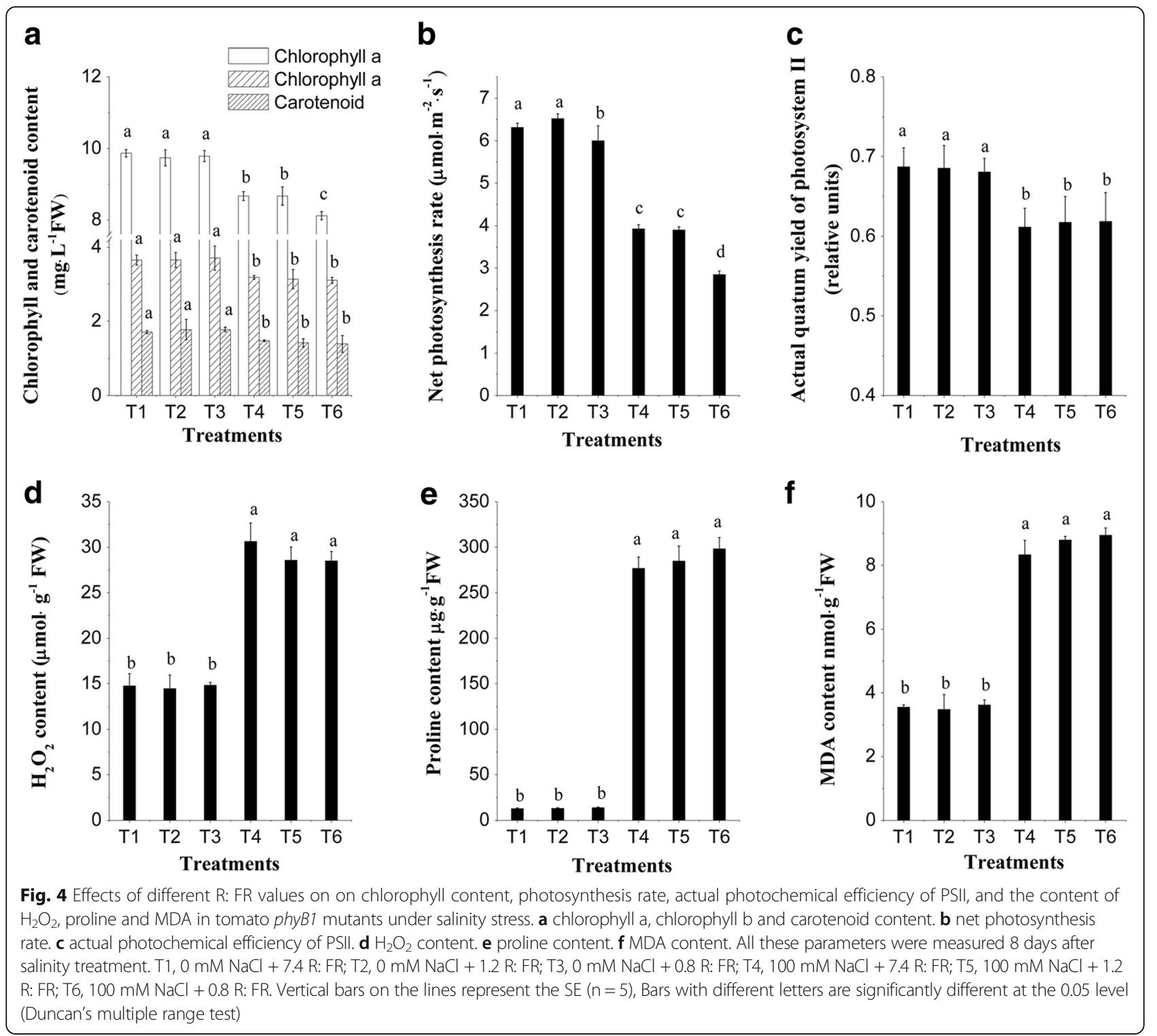

compounds, including antioxidant enzymes and protective proteins $[39,40]$.

Salinity is known to influence chlorophyll synthesis and photosynthesis in a number of plant species, and chlorophyll content tends to positively correlate with photosynthetic rate $[31,32]$. Previous studies have found that salinity stress and a lower R: FR value inhibits the biosynthesis of chlorophyll [29, 37]. However, in our study, the upregulation of $\mathrm{Chl} \mathrm{a}, \mathrm{Chl} \mathrm{b}$, and the net photosynthesis rate were observed in tomato leaves under salinity when exposed to a lower R: FR condition (Fig. 3). To explain these results, further studies on the interaction between salinity and the R: FR value on chlorophyll biosynthesis need to be performed. Maybe salinity and the R: FR value influence chlorophyll biosynthesis in different ways, and a lower R: FR value may help protect chlorophyll biosynthetic enzymes or products that were damaged by salinity. Wang et al. [41] reported that lower R: FR light conditions significantly alleviate PSII and PSI photoinhibition in the shade leaves of tomato plants, and lower R: FR illumination induced nonphotochemical quenching of chlorophyll a fluorescence and increased the activities of Foyer-Halliwell-Asada cycle enzymes and cyclic electron flux (CEF) around PSI. The parameters of the actual quantum yield of photosynthesis (ФPSII), electron transport rate (ETR), and photochemical quenching (qP) have been used extensively to examine the photosynthetic efficiency of different crop plants subjected to salinity stress [32]. Under salinity, the highest ФPSII, ETR, and qP values were observed in the lower R: FR condition, suggesting that a lower R: FR condition alleviated the salinity-induced inhibition of PSII electron transport, 
allowing tomato seedlings to effectively tolerate the stress. These results are in agreement with those of Shu et al. [32], who reported that exogenous materials could relieve salinity-induced inhibition of electron transport at the acceptor side of the PSII reaction center.

Phytochromes are involved in plant tolerate to biotic and abiotic stressors [10, 26, 29, 42]. Tomato contains five phytochrome genes, named PHYA, PHYB1, PHYB2, PHYE and PHYF [43]. In tomato, PHYB1 is mainly involved in the response to $\mathrm{R}$ and FR light, and controls seedling hypocotyl elongation, anthocyanin accumulation, cotyledon expansion, flowering, and abiotic tolerance $[10,44]$. This study demonstrated that different values of R: FR had a significant influence on the salinity tolerance of wild type tomato seedlings, however, some of the influence disappeared in the tomato phyB1 mutants. In the tomato phyB1 mutant, plant height, stem diameter, fresh and dry weight of root, stem and leaf, chlorophyll b and carotenoid amount, ФPSII, MDA, proline, and $\mathrm{H}_{2} \mathrm{O}_{2}$ content did not significantly change when different R: FR treatments were applied under salinity conditions. However, these parameters significantly changed in wild type tomato seedlings after lower R: FR treatments under salinity conditions. These results suggest that a lower R: FR condition improved tomato salinity stress tolerance, and phytochrome B1 play an very important role in this process. Although the role of phytochromes under abiotic stress conditions is largely unknown, there are many reports indicating that phytochromes might mediate the abiotic stress response in plants to control antioxidant enzymes like peroxidases and non-enzymatic antioxidants such as ascorbate, carotenoids, and flavonoids under stress conditions [10, 42]. Plants exposed to light with different R: FR values have been reported to control phytohormone biosynthesis (gibberellin, auxin, cytokinins and abscisic acid), which are also involved in plant salinity tolerance [2, 45]. Furthermore, phytochrome regulates the expression of some proteins that mediate salt tolerance [12]. These findings suggested a strong correlation between phytochromes and salinity tolerance that might involve a complex signaling network which has yet to be elucidated.

\section{Conclusion}

This study identified the effect of R: FR values on tomato salinity tolerance. The results suggested that lower R: FR values could significantly alleviate salt-induced oxidative damage on tomato seedlings, most likely through regulation of antioxidant enzymes and non-enzymatic systems, and phytochrome B1 play an very important role in this process. This was associated with an improvement in the PSII electron transport and promoted tomato seedlings growth under salinity conditions. These findings also indicate possible opportunities to explore the relationship between light quality and salinity stress while also supporting future environmental attempts to improve tolerance to salinity stresses in other crops.

\section{Methods}

Plant material and growth conditions

In this study, cv. MoneyMaker (Solanum lycopersicum L.) wild type and MoneyMaker backgrounded phytochrome B1 mutant (phyB1) were used as the experimental organism. The mutant was provided by the Tomato Genetic Resource Center (Department of Vegetable Crops, University of California, Davis), TGR accession number LA4357. Tomato seeds were soaked for $30 \mathrm{~min}$ in $50 \%$ bleach, then rinsed in running water thoroughly and directly sown on germination paper and incubated at $25{ }^{\circ} \mathrm{C}$. After germination, seedlings were sowed into commercial substrate on polystyrene plugs (plug size: $50 \mathrm{~cm} \times 25 \mathrm{~cm} \times 4.5 \mathrm{~cm}$; 50 cavities very plug, one seed per cavity). Seedlings were grown in a growth chamber under day-neutral conditions (12 h light/12 h dark), maintained constantly at $24-26{ }^{\circ} \mathrm{C}$ with $40-45 \%$ relative humidity. When the second leaf fully expanded, the same sized seedlings were selected and washed to remove the commercial substrate, and then transplanted on foam plates to be grown hydroponically in the growth chamber (Northwest A\&F University, Yangling, Shaanxi, China). The growth chamber was an airtight space, equipped with a lighting system and air conditioner cooling and heating system.

The growth chamber was maintained at $29-31^{\circ} \mathrm{C}$ during the day with $70-80 \%$ relative humidity, and $24-26^{\circ}$ $\mathrm{C}$ during the night with $40-50 \%$ relative humidity $(12 \mathrm{~h}$ light/12 h dark). The growth chamber had six sections, divided by an opaque silvery cloth, with 36 seedlings in each section. The growth chamber used light-emitting diodes with an intensity of $200-230 \mu \mathrm{mol} \cdot \mathrm{m}^{-2} \cdot \mathrm{s}^{-1}$. The seedlings were grown with Yamasaki tomato nutrient solution at 0.5 concentration $(\mathrm{pH}$ 6.0-6.5, EC: $1.3-$ $1.5 \mathrm{~ms} \cdot \mathrm{cm}^{-1}$ ), with dissolved oxygen maintained by air pump at $80 \pm 0.2 \mathrm{mg} \cdot \mathrm{L}^{-1}$.

\section{Salinity and R: FR light treatment}

After 3 days of pre-culture under normal conditions, treatments with salt $(\mathrm{NaCl})$ and three different $\mathrm{R}$ : FR were applied. We use white LED (peaked at 455 and $570 \mathrm{~nm}$ ) and FR LED (peaked at $730 \mathrm{~nm}$ ) to justify tomato growth light environment. The experimental plots included six treatments: (1) T1, $0 \mathrm{mM} \mathrm{NaCl}+7.4 \mathrm{R}$ : FR, (2) $\mathrm{T} 2,0 \mathrm{mM} \mathrm{NaCl}+1.2 \mathrm{R}: \mathrm{FR}$, (3) $\mathrm{T} 3,0 \mathrm{mM} \mathrm{NaCl}+0.8$ R: FR, (4) T4, $100 \mathrm{mM} \mathrm{NaCl}+7.4 \mathrm{R}: \mathrm{FR}$, (5) T5, $100 \mathrm{mM}$ $\mathrm{NaCl}+1.2 \mathrm{R}: \mathrm{FR}$, (6) T6, $100 \mathrm{mM} \mathrm{NaCl}+0.8 \mathrm{R}$ : FR. The light intensity and spectrum were measured by a spectroradiometer (PAR-NIR, Apogee Instruments Inc., Logan, UT) and are shown in Fig. 5. For the purposes of 


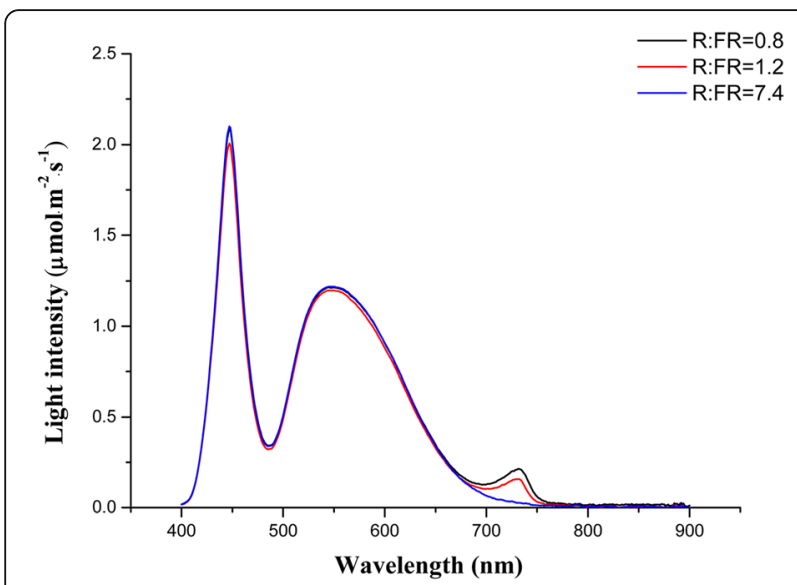

Fig. 5 Spectral distribution characteristics of white and FR LED used for different R: FR treatments. The black curve represents $R$ : FR value is 0.8 , the red curves represents $R$ : FR value is 1.2 ; blue curve represents $R$ : FR value is 7.4

this experiment, the $\mathrm{R}: \mathrm{FR}=$ (photon irradiance between 655 and $665 \mathrm{~nm}$ ) / (photon irradiance between 725 and $735 \mathrm{~nm}$ ). The nutrient solutions were renewed every 2 days. After $8 \mathrm{~d}$ of salinity treatment, the tomato seedlings growth parameters were measured. Tomato wild type samplings were carried out $0,2,4,6$ and $8 \mathrm{~d}$ after treatments, phyB1 mutant samples were carried out $8 \mathrm{~d}$ after treatments, and rapidly frozen these samples in liquid nitrogen and stored at $-80{ }^{\circ} \mathrm{C}$ for biochemical analysis, and 3 replicates were used for each analysis.

\section{Determination of growth parameters}

Ten tomato seedlings in each treatment was used to measure the growth parameters. Stem height was measured by a ruler and stem diameter was measured using digital calipers (Digimatic Caliper; Shengli Co., Ltd., Beijing, China). To determine the fresh weight of the root, stem, and leaf, plants were harvested separately, washed with sterile distilled water, and weighed by a balance. The dry weight of plant root, stem, and leaf were determined after drying at $70{ }^{\circ} \mathrm{C}$ for 2 days and weighed by a balance.

\section{Determination of proline content}

The concentration of proline was prepared and estimated following the method of Gururani et al. [11]. From each treatment, tomato leaf $(0.2 \mathrm{~g})$ was homogenized in $2 \mathrm{~mL}$ of $3 \%(w / v)$ sulfosalicylic acid, then centrifuged $\left(15,000 \mathrm{~g}, 10 \mathrm{~min}, 25^{\circ} \mathrm{C}\right)$. Then, $0.5 \mathrm{~mL}$ glacial acetic acid and $0.5 \mathrm{~mL} 2.5 \%$ ninhydrin solution were added into $0.5 \mathrm{~mL}$ supernatant. The mixture was heated at $100{ }^{\circ} \mathrm{C}$ for $30 \mathrm{~min}$ in a water bath, cooled in an ice bath, then added to $1.5 \mathrm{~mL}$ toluene and allowed to rest for at least $10 \mathrm{~min}$ to allow the phases to separate. The absorbance of the toluene fraction was read at $520 \mathrm{~nm}$.
The proline content was determined by a calibration curve operated in a similar way with solutions of proline at different concentrations.

\section{Determination of malondialdehyde (MDA) content}

Oxidative damage to lipids was estimated by measuring the content of MDA. One gram of plant material from each treatment was homogenized with $5 \mathrm{~mL} 5 \%(\mathrm{w} / \mathrm{v})$ trichloroacetic acid (TCA), then centrifuged $(15,000 \mathrm{~g}$, $15 \mathrm{~min}, 4{ }^{\circ} \mathrm{C}$ ) and added to $5 \%$ trichloroacetic acid containing $0.65 \%(\mathrm{w} / \mathrm{v}) 2$-thiobarbituric acid (TBA) in $2 \mathrm{~mL}$ supernatant. The mixture was heated at $100{ }^{\circ} \mathrm{C}$ for $15 \mathrm{~min}$ in a water bath and then quickly cooled on ice, then the contents were centrifuged $(15,000 \mathrm{~g}, 15 \mathrm{~min}$, $4{ }^{\circ} \mathrm{C}$ ) and the absorbance was read at $532 \mathrm{~nm}$, as described by Huang et al. [28].

\section{Determination of electrolyte leakage}

The total inorganic ions that leaked out of the leaves were measured by the method described by Abo-Ogiala et al. [17]. Ten leaf disks were cut, weighed, and subsequently placed at room temperature into Falcon tubes containing $10 \mathrm{~mL}$ of deionized water. Conductivity of the deionized water $\left(\mathrm{EC}_{0}\right)$ and soaked plant tissue was measured after $24 \mathrm{~h}\left(\mathrm{EC}_{1}\right)$ using a conductivity meter (DDSJ-308A, Shanghai Jingke Instrument Co., Ltd., China). To determine the maximum electrolyte leakage $\left(E C_{2}\right)$, the samples were boiled at $100{ }^{\circ} \mathrm{C}$ for $20 \mathrm{~min}$ and then cooled at room temperature. The relative electrolyte leakage (\%) was calculated as: $\left(\mathrm{EC}_{1}-\mathrm{EC}_{0}\right)$ / $\left(\mathrm{EC}_{2}-\mathrm{EC}_{0}\right) \times 100 \%$.

\section{Determination of $\mathrm{H}_{2} \mathrm{O}_{2}$ and $\mathrm{O}_{2}^{--}$}

To determine $\mathrm{O}_{2}{ }^{\cdot-}$, the assay was done as described by Zhao et al. [46] with some modifications. A section of plant leaf $(0.3 \mathrm{~g})$ was homogenized with $3 \mathrm{~mL} 50 \mathrm{mM}$ phosphate buffer $(\mathrm{pH} 7.8)$ and centrifuged $(12,000 \mathrm{~g}$, $20 \mathrm{~min}, 4^{\circ} \mathrm{C}$ ). One $\mathrm{mL}$ of hydroxylamine hydrochloride was added to $1 \mathrm{~mL}$ of the supernatant, and the mixture was incubated at $25{ }^{\circ} \mathrm{C}$ for $20 \mathrm{~min}$. One $\mathrm{mL}$ of $17 \mathrm{mM}$ $\gamma$-amino-phenylsulfonic and $1 \mathrm{~mL}$ of $7 \mathrm{mM}$ $\alpha$-amino-phenylsulfonic were added to the mixture for another 20 -min incubation at $30{ }^{\circ} \mathrm{C}$. The absorption of the reaction mixture was monitored at $530 \mathrm{~nm}$. $\mathrm{O}_{2}{ }^{\cdot-}$ was calculated according to a standard curve based on Sodium nitrite.

The concentration of $\mathrm{H}_{2} \mathrm{O}_{2}$ was prepared and estimated following the method of Gururani et al. [26], with slight modifications. Fresh samples of leaf $(0.5 \mathrm{~g})$ were homogenized with $5 \mathrm{~mL} 0.1 \%(w / v)$ TCA in an ice bath, and the homogenate was centrifuged at $12,000 \mathrm{~g}$ for $15 \mathrm{~min}$. Then, $0.5 \mathrm{~mL}$ of $100 \mathrm{mM}$ potassium phosphate buffer ( $\mathrm{pH} 7.0)$ and $1 \mathrm{~mL}$ of $1 \mathrm{M}$ KI were added to $0.5 \mathrm{~mL}$ of the supernatant. The absorbance of 
supernatant was read at $390 \mathrm{~nm}$, and the content of $\mathrm{H}_{2} \mathrm{O}_{2}$ was calculated based on a standard curve.

\section{Assay of soluble protein and antioxidant enzymes (SOD, POD, and CAT)}

Fresh tomato leaf $(0.3 \mathrm{~g})$ from each treatment was crushed into fine powder in a pestle and mortar using liquid nitrogen. The powder was homogenized in $3 \mathrm{~mL}$ of $50 \mathrm{mM}$ pre-cooled phosphate buffer ( $\mathrm{pH}$ 7.8). The homogenate was centrifuged $\left(12,000 \mathrm{~g}, 20 \mathrm{~min}, 4{ }^{\circ} \mathrm{C}\right)$, and the supernatant was used for enzyme activity assays. Protein content was evaluated according to the method of Huang et al. [28], using bovine serum albumin as the standard.

Total SOD activity was determined by the inhibition of the photochemical reduction of nitroblue tetrazolium (NBT), as described by Moradi and Ismail [31], with slight modifications. The reaction mixture consisted of $0.1 \mathrm{~mL}$ of enzyme extract and $5 \mathrm{~mL} \mathrm{O}_{2}{ }^{\cdot-}$ generating solution which contained $4 \mathrm{~mL} 14.5 \mathrm{mM}$ methionine, $0.02 \mathrm{~mL} 30 \mu \mathrm{M}$ EDTA- $\mathrm{Na}_{2}, 0.4 \mathrm{~mL} 750 \mu \mathrm{M} \mathrm{NBT}$, and $0.4 \mathrm{~mL} 20 \mu \mathrm{M}$ of riboflavin. Extracts were brought to a final volume of $0.18 \mathrm{~mL}$ with $50 \mathrm{mM} \mathrm{Na-phosphate}$ (pH 7.8). Test tubes were shaken and placed $30 \mathrm{~cm}$ under lights for 15-min. The enzyme unit was defined as the inhibition of the photochemical reduction of $50 \%$ NBT by the reaction system per minute at $560 \mathrm{~nm}$, using a Multiple-label Multifunctional Microplate reader (spectraMax i3x, Molecular Devices Inc., United States). Enzyme activity was expressed as U. $\mathrm{mg}^{-1}$ protein.

CAT activity was determined by the reduction of $\mathrm{H}_{2} \mathrm{O}_{2}$ at $240 \mathrm{~nm}$ spectrophotometrically, as described by Gururani et al. [26], with some modifications. The reaction mixture contained $13.6 \mathrm{mM} \mathrm{H}_{2} \mathrm{O}_{2}$ in $15 \mathrm{mM}$ phosphate buffer $(\mathrm{pH} 7)$. The reaction was initiated by the addition of the enzyme extract. POD activity was determined with guaiacol as the reducing substrate in a reaction mixture containing $0.2 \mathrm{M} \mathrm{Na}$-phosphate buffer (pH 6), $3 \mathrm{mM}$ guaiacol, and $4.9 \mathrm{mM} \mathrm{H}_{2} \mathrm{O}_{2}$. The oxidation of guaiacol was assessed by recording the absorbance increase at $470 \mathrm{~nm}$. One unit of CAT and POD was defined as the amount of enzyme which produced a change of 0.1 in absorbance at $240 \mathrm{~nm}$ and $470 \mathrm{~nm}$, respectively, per minute, at $25{ }^{\circ} \mathrm{C}$. The enzyme activities of POD and CAT were expressed as U.mg ${ }^{-1}$ protein.

\section{Chlorophyll concentration and photosynthetic rate analysis}

Tomato leaf (0.3 g) was soaked in 95\% alcohol for extraction. The samples were then stored at $25{ }^{\circ} \mathrm{C}$ for $24 \mathrm{~h}$. The absorbance was read at 665, 649 and $470 \mathrm{~nm}$. The concentrations of chlorophyll $a$, chlorophyll $b$ and cartotenoid were calculated according to Fan et al. [27].

Net photosynthesis rate (Pn) and the light responsiveness curve of tomato leaves were determined using the second fully expanded leaves between 9:00 am and 11:00 am on a portable photosynthesis system (LI6400, LI-COR Inc., USA). In the assimilation chamber, leaf temperature was $25{ }^{\circ} \mathrm{C}$, relative humidity was $85 \%$, ambient $\mathrm{CO}_{2}$ concentration was $400 \pm$ $10 \mathrm{ppm}$, and photosynthetic photon flux density (PPFD) was $200 \mu \mathrm{mol} \cdot \mathrm{m}^{-2} \cdot \mathrm{s}^{-1}$.

\section{Chlorophyll fluorescence parameters}

Chlorophyll fluorescence emission from the upper surface of the second fully expanded leaves of intact plants was measured by a modulated fluorimeter (PAM Photosynthesis Yield Analyser, Walz, Effeltrich, Germany), according to Moradi and Ismail [31]. The minimal (Fo) and maximal (Fm) chlorophyll fluorescence emissions were assessed in leaves after 30-min of dark adaptation. To determine the minimal fluorescence level in a leaf during illumination (Fo'), and to allow maximal oxidation of the PSII centers in the presence of far-red light, a black cloth was rapidly placed over the plants to block out light, causing the leaf fluorescence to fall to the Fo' level, rising again after a few seconds. Then, the leaves were continuously illuminated with a white actinic light, which was equivalent to the actual growth lights used for the tomato plants, to measure both steady-state (Fs) and the maximal chlorophyll fluorescence level in light-adapted leaves ( $\left.\mathrm{Fm}^{\prime}\right)$. From these measurements, the actual photochemical efficiency of PSII [ФPSII $=(\mathrm{Fm}$ '- Fs) / Fm'], the photochemical quenching coefficient $\left[\mathrm{qP}=\left(\mathrm{Fm}^{\prime}-\mathrm{Fs}\right) /\left(\mathrm{Fm}^{\prime}-\mathrm{Fo}^{\prime}\right)\right]$, electron transport rate $(\mathrm{ETR}=$ ФPSII $\times$ PPFD $\times 0.5 \times 0.87)$ were calculated, where PPFD is the photosynthetic photon flux density incident on the leaf, 0.5 is a factor that assumes equal distribution of energy between the two photosystems, and 0.87 is an assumed factor of leaf absorbance.

\section{Statistical analysis}

Statistics were calculated using SPSS 20.0 (SPSS, version 20.0, IBM Inc., USA). The data were analyzed by analysis of variance (ANOVA), and the differences between the means were assessed by Duncan's multiple range test $(P<$ $0.05)$. Error bars in all figures represent standard deviation from the mean. Graphs were created using OriginPro (version 8.0, Origin Lab, MA, USA).

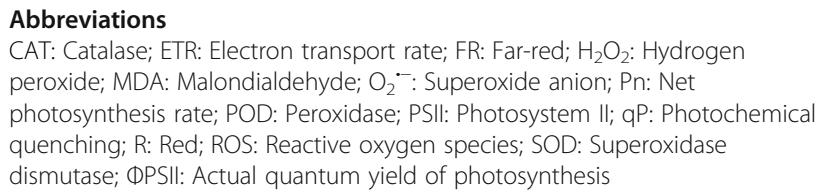

\section{Acknowledgements}

This research was supported financially by the Key Laboratory of Protected Horticultural Engineering in Northwest, Ministry of Agriculture, PR China, We are grateful for tomato mutants obtained from the Genetic Resource Center (Department of Vegetable Crops, University of California, Davis). 


\section{Funding}

This research was funded by the study on key technologies for healthy production of efficient resources utilization in protected vegetables (2016BZ09), by research on key technologies and supporting equipment of protected vegetable production (CX161002), and by the achievement transformation of multilayer stereo water culture (AA16380048).

\section{Availability of data and materials}

Plant materials in this work and datasets analysed during the current study are available from the corresponding author upon request.

\section{Authors' contributions}

$\mathrm{ZZ}$ and $\mathrm{KC}$ conceived the study. ZZ and KC designed the experiments. KC carried out the chlorophyll concentration, photosynthetic rate and chlorophyll fluorescence parameters studies, and revised the manuscript. JY and DX carried out the biochemicals and antioxidant system studies. KA and EB interpreted the experimental data. All authors read and approved the final manuscript.

\section{Ethics approval and consent to participate}

Not applicable.

\section{Competing interests}

The authors declare that they have no competing interests.

\section{Publisher's Note}

Springer Nature remains neutral with regard to jurisdictional claims in published maps and institutional affiliations.

\section{Author details}

${ }^{1}$ Horticulture College, Northwest A\&F University, Yangling, Shaanxi, China. ${ }^{2}$ The Agriculture Ministry Key Laboratory of Agricultural Engineering in the Middle and Lower Reaches of Yangze River, Nanjing, China. ${ }^{3}$ Guangxi Zhong Nong Fu Yu International Agricultural Science and Technology Co., Ltd, Yulin, Guangxi, China.

\section{Received: 9 October 2017 Accepted: 14 May 2018}

\section{Published online: 24 May 2018}

\section{References}

1. Carvalho RF, Takaki M, Azevedo RA. Plant pigments: the many faces of light perception. Acta Physiol Plant. 2011;33(2):241-8.

2. Franklin KA, Quail PH. Phytochrome functions in Arabidopsis development. J Exp Bot. 2010;61(1):11-24.

3. Hayes S, Sharma A, Fraser DP, Trevisan M, Cragg-Barber CK, Tavridou E, Fankhauser C, Jenkins Gl, Franklin KA. UV-B perceived by the UVR8 photoreceptor inhibits plant thermomorphogenesis. Curr Biol. 2017;27(1): $120-7$.

4. Liu B, Yang Z, Gomez A, Liu B, Lin C, Oka Y. Signaling mechanisms of plant cryptochromes in Arabidopsis thaliana. J Plant Res. 2016;129(2):137-48.

5. Müller P, Bouly J-P. Searching for the mechanism of signalling by plant photoreceptor cryptochrome. FEBS Lett. 2015;589(2):189-92.

6. Chen M, Tao Y, Lim J, Shaw A, Chory J. Regulation of phytochrome B nuclear localization through light-dependent unmasking of nuclearlocalization signals. Curr Biol. 2005;15(7):637-42.

7. Ádám É, Hussong A, Bindics J, Wüst F, Viczián A, Essing M, Medzihradszky M, Kircher S, Schäfer E, Nagy F. Altered dark-and photoconversion of phytochrome B mediate extreme light sensitivity and loss of photoreversibility of the phyB-401 mutant. PLoS One. 2011;6(11):e27250.

8. Possart A, Xu T, Paik I, Hanke S, Keim S, Hermann H-M, Wolf L, Hiss M, Becker C, Huq E. Characterization of Phytochrome interacting factors from the Moss Physcomitrella Patens illustrates conservation of Phytochrome signaling modules in land plants. Plant Cell. 2017;29(2):310-30.

9. Sheerin DJ, Menon C, zur Oven-krockhaus S, Enderle B, Zhu L, Johnen P, Schleifenbaum F, Stierhof Y-D, Huq E, Hiltbrunner A. Light-activated phytochrome $a$ and $B$ interact with members of the SPA family to promote photomorphogenesis in Arabidopsis by reorganizing the COP1/SPA complex. Plant Cell. 2015;27(1):189-201.

10. Gavassi MA, Monteiro CC, Campos ML, Melo HC, Carvalho RF. Phytochromes are key regulators of abiotic stress responses in tomato. Sci Hortic. 2017;222: $126-35$.
11. Gururani MA, Upadhyaya CP, Strasser RJ, Yu JW, Park SW. Evaluation of abiotic stress tolerance in transgenic potato plants with reduced expression of PSII manganese stabilizing protein. Plant Sci. 2013;198:7-16.

12. Indorf M, Cordero J, Neuhaus G, Rodríguez-Franco M. Salt tolerance (STO), a stress-related protein, has a major role in light signalling. Plant J. 2007;51(4): 563-74.

13. Shibuya T, Itagaki K, Tojo M, Endo R, Kitaya Y. Fluorescent illumination with high red-to-far-red ratio improves resistance of cucumber seedlings to powdery mildew. HortScience. 2011;46(3):429-31.

14. Wit M, Spoel SH, Sanchez-Perez GF, Gommers CM, Pieterse CM, Voesenek LA, Pierik R. Perception of low red: far-red ratio compromises both salicylic acid-and jasmonic acid-dependent pathogen defences in Arabidopsis. Plant J. 2013;75(1):90-103.

15. Zhao Y, Zhou J, Xing D. Phytochrome B-mediated activation of lipoxygenase modulates an excess red light-induced defence response in Arabidopsis. J Exp Bot. 2014;65(17):4907-18.

16. Liu J, Zhang F, Zhou J, Chen F, Wang B, Xie X. Phytochrome B control of total leaf area and stomatal density affects drought tolerance in rice. Plant Mol Biol. 2012;78(3):289-300.

17. Abo-Ogiala A, Carsjens C, Diekmann H, Fayyaz P, Herrfurth C, Feussner I, Polle A. Temperature-induced lipocalin (TIL) is translocated under salt stress and protects chloroplasts from ion toxicity. J Plant Physiol. 2014; 171(3):250-9.

18. Adem GD, Roy SJ, Zhou M, Bowman JP, Shabala S. Evaluating contribution of ionic, osmotic and oxidative stress components towards salinity tolerance in barley. BMC Plant Biol. 2014;14(1):113.

19. Geilfus CM, Mithöfer A, Ludwig-Müller J, Zörb C, Muehling KH. Chlorideinducible transient apoplastic alkalinizations induce stomata closure by controlling abscisic acid distribution between leaf apoplast and guard cells in salt-stressed Vicia faba. New Phytol. 2015;208(3):803-16.

20. Orsini F, Accorsi M, Gianquinto G, Dinelli G, Antognoni F, Carrasco KBR, Martinez EA, Alnayef M, Marotti I, Bosi S. Beyond the ionic and osmotic response to salinity in Chenopodium quinoa: functional elements of successful halophytism. Funct Plant Biol. 2011;38(10):818-31.

21. Miller G, Suzuki N, CIFTCI-YILMAZ S, Mittler R. Reactive oxygen species homeostasis and signallinge during drought and salinity stresses. Plant Cell Environ. 2010;33(4):453-67.

22. Saxena B, Shukla K, Giri B. Arbuscular mycorrhizal Fungi and tolerance of salt stress in plants. In: Arbuscular Mycorrhizas and Stress Tolerance of Plants. Springer; 2017. p. 67-97.

23. Vijayalakshmi T, Vijayakumar A, Kiranmai K, Nareshkumar A, Sudhakar C. Salt stress induced modulations in growth, compatible solutes and antioxidant enzymes response in two cultivars of safflower (Carthamus tinctorius L. cultivar TSF1 and cultivar SM) differing in salt tolerance. Am J Plant Sci. 2016;7(13):1802.

24. Kim Y, Kim I, Shin S, Park T, Park H, Kim Y, Lee G, Kang H, Lee S, Yoon H. Overexpression of dehydroascorbate reductase confers enhanced tolerance to salt stress in rice plants (Oryza sativa L. japonica). J Agron Crop Sci. 2014; 200(6):444-56.

25. Prashanth S, Sadhasivam V, Parida A. Over expression of cytosolic copper/ zinc superoxide dismutase from a mangrove plant Avicennia marina in indica rice var Pusa Basmati-1 confers abiotic stress tolerance. Transgenic Res. 2008;17(2):281-91.

26. Gururani MA, Ganesan M, Song I-J, Han Y, Kim J-I, Lee H-Y, Song P-S. Transgenic turfgrasses expressing hyperactive Ser599Ala Phytochrome a mutant exhibit abiotic stress tolerance. J Plant Growth Regul. 2016;35(1): $11-21$.

27. Fan X, Zang J, Xu Z, Guo S, Jiao X, Liu X, Gao Y. Effects of different light quality on growth, chlorophyll concentration and chlorophyll biosynthesis precursors of non-heading Chinese cabbage (Brassica campestris L.). Acta Physiol Plant. 2013;35(9):2721-6.

28. Huang C-J, Wei G, Jie Y-C, Xu J-J, Zhao S-Y, Wang L-C, Anjum S. Responses of gas exchange, chlorophyll synthesis and ROS-scavenging systems to salinity stress in two ramie Boehmeria nivea. Photosynthetica. 2015;53(3): 455-63.

29. Demotes-Mainard S, Péron T, Corot A, Bertheloot J, Le Gourrierec J, Pelleschi-Travier S, Crespel L, Morel P, Huché-Thélier L, Boumaza R. Plant responses to red and far-red lights, applications in horticulture. Environmental and Experimental Botany. 2016;121:4-21.

30. Demidchik V, Straltsova D, Medvedev SS, Pozhvanov GA, Sokolik A, Yurin V. Stress-induced electrolyte leakage: the role of $\mathrm{K}_{+-}$-permeable channels and 
involvement in programmed cell death and metabolic adjustment. J Exp Bot. 2014;65(5):1259-70.

31. Moradi F, Ismail AM. Responses of photosynthesis, chlorophyll fluorescence and ROS-scavenging systems to salt stress during seedling and reproductive stages in rice. Ann Bot. 2007:99(6):1161-73.

32. Shu S, Yuan L-Y, Guo S-R, Sun J, Yuan Y-H. Effects of exogenous spermine on chlorophyll fluorescence, antioxidant system and ultrastructure of chloroplasts in Cucumis sativus L. under salt stress. Plant Physiol Biochem. 2013;63:209-16.

33. Hertel $\mathrm{C}$, Leuchner $\mathrm{M}$, Menzel A. Vertical variability of spectral ratios in a mature mixed forest stand. Agric For Meteorol. 2011;151(8):1096-105.

34. Holmes M, Smith $\mathrm{H}$. The function of phytochrome in the natural environment - I. Characterization of daylight for studies in photomorphogenesis and photoperiodism. Photochem Photobiol. 1977; 25(6):533-8.

35. Nagasuga K, Kubota F. Effects of shading on hydraulic resistance and morphological traits of internode and node of napiergrass (Pennisetum purpureum Schumach.). Plant production science. 2008;11(3):352-4.

36. Yan Y, Gong W, Yang W, Wan Y, Chen X, Chen Z, Wang L. Seed treatment with uniconazole powder improves soybean seedling growth under shading by corn in relay strip intercropping system. Plant production science. 2010:13(4):367-74.

37. Parvaiz A, Satyawati S. Salt stress and phyto-biochemical responses of plants-a review. Plant Soil and Environment. 2008;54(3):89.

38. Abogadallah GM. Insights into the significance of antioxidative defense under salt stress. Plant Signal Behav. 2010;5(4):369-74

39. Dong C, Fu Y, Liu G, Liu H. Growth, photosynthetic characteristics, antioxidant capacity and biomass yield and quality of wheat (Triticum aestivum L.) exposed to LED light sources with different spectra combinations. J Agron Crop Sci. 2014;200(3):219-30.

40. Manivannan A, Soundararajan P, Halimah N, Ko CH, Jeong BR. Blue LED light enhances growth, phytochemical contents, and antioxidant enzyme activities of Rehmannia glutinosa cultured in vitro. Hortic Environ Biotechnol. 2015;56(1):105-13.

41. Wang F, Wu N, Zhang L, Ahammed GJ, Chen X, Xiang X, Zhou J, Xia X, Sh $K$, Yu J, et al. Light signaling-dependent regulation of Photoinhibition and Photoprotection in tomato. Plant Physiol. 2018:176(2):1311-26.

42. Alves FRR, de Melo HC, Crispim-Filho AJ, Costa AC, Nascimento KJT, Carvalho RF. Physiological and biochemical responses of photomorphogenic tomato mutants (cv. Micro-tom) under water withholding. Acta Physiol Plant. 2016;38(6):155.

43. Hauser BA, Pratt LH, Cordonnier-Pratt M-M. Absolute quantification of five phytochrome transcripts in seedlings and mature plants of tomato (Solanum lycopersicum L.). Planta. 1997;201(3):379-87.

44. Weller $J L$, Schreuder ME, Smith H, Koornneef M, Kendrick RE. Physiological interactions of phytochromes a, B1 and B2 in the control of development in tomato. Plant J. 2000;24(3):345-56.

45. Fahad S, Hussain S, Matloob A, Khan FA, Khaliq A, Saud S, Hassan S, Shan D, Khan F, Ullah N. Phytohormones and plant responses to salinity stress: a review. Plant Growth Regul. 2015;75(2):391-404.

46. Zhao H, Ye L, Wang Y, Zhou X, Yang J, Wang J, Cao K, Zou Z. Melatonin increases the chilling tolerance of chloroplast in cucumber seedlings by regulating photosynthetic electron flux and the ascorbate-glutathione cycle. Front Plant Sci. 2016;7

\section{Ready to submit your research? Choose BMC and benefit from:}

- fast, convenient online submission

- thorough peer review by experienced researchers in your field

- rapid publication on acceptance

- support for research data, including large and complex data types

- gold Open Access which fosters wider collaboration and increased citations

- maximum visibility for your research: over $100 \mathrm{M}$ website views per year

At BMC, research is always in progress.

Learn more biomedcentral.com/submissions 